Is It in Charlie Gard's Best Interest to Die?

Julian Savulescu, MB, BS, PhD

Uehiro Chair in Practical Ethics

Director, Oxford Uehiro Centre for Practical Ethics, University of Oxford

Lulian.savulescu@philosophy.ox.ac.uk

Oxford Uehiro Centre for Practical Ethics, Suite 8, Littlegate House, 16/17 St Ebbe's St, Oxford, OX1 1PT, UK. 


\section{Is It in Charlie Gard's Best Interest to Die?}

On the $11^{\text {th }}$ of May, the High Court ruled that it is in Charlie Gard's best interests to die. The judge explained: "although the parents have parental responsibility, overriding control is vested in the court exercising its independent and objective judgment in the child's best interests." 1

The judge referred to previous judgement: "There is a strong presumption in favour of a course of action which will prolong life, but that presumption is not irrebuttable. The term "best interests" encompasses medical, emotional, and all other welfare issues." 2 In other judgements, life has been deemed not in the child's interests when it would be: "intolerable to the child" and "bound to be full of pain and suffering"3

It is not clear, however, that exactly what these criteria mean and whether Charlie Gard's life meets them.

Charlie s life currently lacks any well-being, and he experiences discomfort related to intensive care (suctioning, invasive procedures, etc) and epileptic seizures. However, these can be managed with medical treatment, such as sedation and analgesia. Experimental nucleoside replacement therapy offers a very small but non-zero chance of some improvement. His final capacity for experiencing pleasure and engagement in social relationships are unclear. Many severely disabled people, even on long term ventilation, value their lives and it is not clear that continued life is against their interests.

The claim that Gard's life is objectively against his interests turns, crucially, on the claim that a very small chance of a small improvement is outweighed by the suffering attending his condition and its treatment. But this not an "objective" "fact" but a value judgement. There is space for reasonable disagreement. For example, is a 1/10 000 chance of improvement worth some months of "unpleasantness", of needles and invasive procedures? There is inevitably the escape to euphemisms like "death with dignity".

Having spent 20 years in medical ethics, I do believe some lives are intolerable and not worth living, but this is extremely rare. The best example is severe dystrophic Epidermolysis Bullosa. In this condition, the skin relentlessly peels off, causing extreme pain and infection. In the most severe form, the child often dies of infection in the first year of life, even with medical therapy. Severe pain is an intrinsic part of the syndrome; this is not the case in Charlie Gard.

How should value judgements be made? Philosopher John Rawls described a process of reflective equilibrium. This involves developing principles (such as the best interests principle and those of distributive justice) and concepts (such as well-being and a life worth living), but crucially revising these in line with intuitions about specific cases, such as Charlie's. This process is what judges engage in but judges, or doctors, are not necessarily or exclusively ethical experts. 
Rawls described the qualities of people who should be engaged in reflective equilibrium. They should be knowledgeable about the relevant facts.

Importantly, they should be "reasonable": (i) being willing to use logic, (ii) being disposed to find reasons for and against a solution, (iii) having an open mind, (iv) making a conscientious effort to overcome intellectual, emotional and moral prejudices. Lastly, they are to have "sympathetic knowledge ... of those human interests which, by conflicting in particular cases, give rise to the need to make a moral decision."4

A group of such people outside the medical and legal professions might either conclude a slim chance of life was worth taking or that they don't know.

Consider the following thought experiment which supports the claim we don't know whether Charlie's life really is "intolerable". Imagine that we discovered a baby like Charlie in the US with an identical condition. However, he was already being treated with nucleoside replacement. He has been deeply sedated. He spends nearly all of his day unconscious on a breathing tube. Once every few days, his sedation is lightened to see if there is any improvement in his condition. Doctors have agreed with parents that if after six months of this treatment there is no improvement, they will stop artificial ventilation and allow this baby to die.

Are these doctors acting in a cruel and inhumane manner? Should courts intervene to protect the baby's interests? Is this baby being forced to live a life which is not worth living and intolerable? Should the experimental treatment and artificial ventilation be stopped and this baby be allowed to "die with dignity" now?

The answer to all these questions is "No". Presumably, many babies have been treated in similar circumstances. Yet we might also believe it would be reasonable for Charlie's parents to have chosen to forgo experimental treatment and allow him to die. This shows it could be reasonable to either give or not give Charlie a trial of therapy. One need not argue that treatment is in Charlie's interests. It is enough to say we don't know. In that case, other considerations, such as the interests or desires of his family (or the social value of engaging in experimentation), can dictate what is done.

Even if it were clearly in Charlie's interests to receive treatment, it could still be withheld on the grounds of distributive justice. ${ }^{5}$ But those grounds don't apply as Charlie's parents have found funds to cover his treatment outside the UK.

Judges must make a decision in these kinds of cases. This decision was reasonable. But a different judge might reasonably decide the opposite.

Acknowledgements:

Wellcome Trust Grant no. WT104848/Z/14/Z

\section{References}

1. Press summary: Great Ormond Street Hospital for Children -v- Gard. 11 April 2017. https://www.judiciary.gov.uk/wp-content/uploads/2017/04/gard-press-summary20170411.pdf. Accessed 1 May 2017. 
2. Wyatt v Portsmouth NHS Trust. 2005. EWHC 117

3. Re J (A Minor)(Wardship: Medical Treatment). 1990. 3 All ER 930. 1991. Fam 33 (CA)

4. Rawls J. Outline of a Decision Procedure for Ethics. Philosophical Review 1951; 60: 177-97.

5. Wilkinson D, Savulescu J. Knowing when to stop: futility in the ICU. Current Opinion in Anaesthesiology 2011; 24:160-165. 